\title{
Evaluation of General Airport Site Selection Based on Synthetic Weighting Method and Grey Fuzzy Theory
}

\author{
Liang Qiao, Liang Zhang \\ Department of Airport Management, Guangzhou Civil Aviation College, Guangzhou, 510830, \\ China
}

Keywords: General airport; site selection; entropy method; grey fuzzy theory.

\begin{abstract}
With the transformation and upgrading of industrial structure in China, the role of general aviation industry in national economy is more and more important. As an early stage of airport construction, the site selection become more critical when the number of general airports increased rapidly. In order to make the airport location more objective, a grey fuzzy evaluation model is built based on synthetic weighting method and grey fuzzy theory. Index weights which are measured by the AHP and entropy weight will be more reasonable. The grey fuzzy theory makes full use of evaluation information to promote the evaluation result more scientific. The model is applied to Mile airport site selection in Yunnan, the result shows that the Dongfeng farm No. 2 site is the best, it is consistent with the actual situation. Moreover, it is confirmed that the model is valid and practical.
\end{abstract}

\section{Introduction}

According to the State Council on"Promoting the Development of General Aviation Industry Guidance" in 2016 and the civil aviation authority concerning "the 13th Five-Year Plan of General Aviation", two hundred airports will be built at least during the next four years in China. In order to ensure these new airports which are in the nodes of aviation network can be operated normally and safely after construction, it should be focus on planning and construction of the general airport in the future.

Site selection is the first step in the construction process of a general airport, and it is also an important basis for the following feasibility study and design. The "General Airport Sort Management Regulations"[1] provides that the investors of any airport construction project should apply to the regional civil aviation authority, the regional civil aviation authority issued audit opinions in accordance with whether an airport site meets the aircraft's take-off and landing requirements and whether it has impacts on adjacent airports. It is thus clear that the site selection of general airport could have a bearing on surrounding social economy, traffic network, ecological environment,airport operation efficiency, investment amount, clearance safety and airspace or route conflict with adjacent airports. The airport site selection is a complex evaluation process, these steps usually include initial selection on the map, preselection after site survey, recommended sites determination after comparison of engineering technology, economy and navigation service, and the final site confirmation before it is reviewed and approved by the regional civil aviation authority and the air force of military region.

In recent years, many experts and scholars have studied and discussed the airport site selection problems from different aspects, and put forward many relevant mathematical models and suggestions. Liao Yong et al. [2] have established a nonlinear integer stochastic programming model with the objective function of minimum travel cost for passenger on the basis of overall consideration of all airports in urban agglomerations. Goo Yong-Qian et al. [3] have made the objective and reasonable evaluation of shipborne heliport site selection by establishing a multilayer grey evaluation model. Wang Jiao-e et al. [4] put forward the two stage method of airport layout planning based on GIS, a multi-objective model of airport layout optimization was built after a discussion about the theory of facility layout and demand distribution. In order to reduce the subjectivity of airport site evaluation index weight, LI Ming-jie et al. used the normalization formula based on catastrophe theory to calculate the rationality and sustainability of airport site selection[5]. DING De-liang et al. considered that the airport site selection is a complex multi-objective optimization problem with many 
influencing factors, therefore, the DAGF model was proposed. The improved Delphi method was adopted to construct the index system of site selection, and the index weight was measured by AHP in the model[6]. WANG Zhen-hui et al.[7] used the interval number instead of the fuzzy number to score the alternatives in a decision matrix. The airport site selection problem was transformed into a single-objective optimization model by using the single objective optimization and interval number theory.

The general airport site evaluation index system includes quantitative index and qualitative index, which belongs to multi-criteria and multilayer fuzzy evaluation. The synthetic evaluation model is built to evaluate the advantages and disadvantages of a general airport site on the basis of the method of AHP-entropy weight and the grey fuzzy theory.

\section{Establishment of the Evaluation Index System for Site Selection}

Section 6.2 of the "General Airport Construction Code"[8] states that the following factors should be taken into account when a general airport site is determined.

Airspace conditions. Any general airport construction not be allowed within a prohibited area unless approved. The risk of aircraft breaking into the prohibited area should be taken into account when a general airport is built in the vicinity of prohibited area. The flight activities in a general airport should be fully considered in coordination with flight restricted area and military airspace.

2) Meteorological conditions. The effects of wind field, precipitation, visibility and other weather conditions on flight safety and airport utilization should be fully considered.

3) Complicated electromagnetic environment. The effects of space electromagnetic environment on airport communication and navigation, and the influence of electromagnetic waves generated by aviation activities on ground sensitive facilities should be fully considered.

4) Bird habitat and migration path. The bird strike risk of aircraft and the impact of flight activities on the living environment of birds should be fully considered.

5) Clearance conditions. Airport obstacles should meet the airport clearance standard, unless it is proved to have no substantial effect.

6) Noise sensitive area. Full consideration should be given to whether the aircraft movement area meets the requirements of the surrounding area noise control indicators.

7) Flammable and explosive facilities on the ground. When a general airport is built in the vicinity of a inflammable and explosive facility on the ground, the needs of the safety distance should be fully taken into account or the flight rules can be changed properly.

8) Construction conditions. The factors such as unfavorable geological area, potentially flooded area, active geological fault zone, mining area, environmental and ecological protection area, tourist attraction, cultural relics and historic site, etc. should be fully considered.

9) Land use. It should be complied with the requirements of relevant land use policies and regulations, such as restrictions on the use of cultivated land and woodland, and wasteland, bad land encouragement development policy.

10) Supporting facilities. It should be taken full account of the availability of road, fire, rescue, water, energy, sewage treatment, communications and other surrounding public facilities.

11) Expansion of airport scale and function. If the scale and function of a general airport needs to be expanded in the future, The land for development should be reserved at the site selection stage.

12) Adjacent airports. The interaction and coordination with surrounding airports in functions, utilization restrictions and other aspects should be fully taken into account.

13) Other factors that are not suitable for general aviation activities.

Referring to the above specification, the multi-level evaluation index system of general airport site is established in consideration of the requirements of planning, environment and economy, technical conditions of project and operation safety, as shown in Table1. 


\section{Construction of the Site Evaluation Model}

\subsection{Sample Matrix and Index Weight.}

It is supposed that the number of experts is ' $\mathrm{p}$ ', the number of alternative sites is ' $m$ ', the number of index in the second level is ' $n$ '. Any index among the second layer of the evaluation index system of general airport site is marked as ' $u_{j}$ ', the expert whose number is 'l' give ' $u_{j}$ ' score marked as ' $d_{j l}$ ' for the site ' $k$ '. An evaluation sample matrix is formed by all ' $d_{j l}$ ' marked as ' $D_{k}$ '. For each and every site, the mean value of all ' $d_{j l}$ ' of each ' $u_{j}$ ' is calculated. This mean value is marked as ' $y_{k j}$ ', another evaluation matrix is formed by all ' $y_{k j}$ ' marked as ' $D$ ' '.

$$
\begin{aligned}
D_{k}=\left(d_{j l}\right)_{n \times p} & =\left[\begin{array}{ccc}
d_{11} & \Lambda & d_{1 n} \\
\mathrm{M} & \Lambda & \mathrm{M} \\
d_{p 1} & \Lambda & d_{p n}
\end{array}\right]^{T} \\
D^{\prime}=\left(y_{k j}\right)_{m \times n} & =\left[\begin{array}{ccc}
y_{11} & \Lambda & y_{11} \\
\mathrm{M} & \mathrm{M} & \mathrm{M} \\
y_{m 1} & \Lambda & y_{m n}
\end{array}\right]^{\prime}
\end{aligned}
$$

The methods of determining the weight of the index mainly include subjective weighting method and objective weighting method. The method of determining weight by expert experience is called subjective weighting method, such as AHP, etc. The method of determining weight by statistical data is called objective weighting method, such as entropy method, PCA, etc. In order to reflect the information contained in the evaluation indicators set and to reduce the result deviation caused by subjective factors, index weights of the general airport site evaluation system are measured by entropy combined with the AHP method. Calculation steps are as follows.

The entropy marked as ' $c_{j}$ ' of the index ' $u_{j}$ ' is calculated for the site ' $\mathrm{k}$ '.

$$
\begin{gathered}
Y_{k j}=\frac{y_{k j}}{\sum_{k=1}^{m} y_{k j}} \\
c_{j}=-\frac{1}{\ln m} \sum_{k=1}^{m} Y_{k j} \ln Y_{k j}
\end{gathered}
$$

The entropy weight marked as ' $w_{j}^{\prime}$ ' of the index ' $u_{j}$ ' is calculated.

$$
w_{j}^{\prime}=\frac{1-c_{j}}{\sum_{j=1}^{n}\left(1-c_{j}\right)}
$$

The synthetic weight marked as ' $w_{j}$ ' of the index ' $u_{j}$ ' is calculated. (Note: the weight of the index ' $u_{j}$ ' measured by the AHP is marked as ' $w_{j}^{\prime \prime}$ )

$$
w_{j}=\frac{w_{j}^{\prime} \cdot w_{j}^{\prime \prime}}{\sum_{j=1}^{n} w_{j}^{\prime} \cdot w_{j}^{\prime \prime}}
$$

The weight vector of the second level index can be obtained as $A=\left(w_{1}, w_{2}, \Lambda, w_{n}\right)$.

\subsection{Evaluation Rating Set.}

Evaluation result can be divided into several levels, ' $v_{i}$ ' represents a certain level, it can get an evaluation rating set marked as $V=\left(v_{1}, v_{2}, \Lambda, v_{g}\right)$. The remark of index is divided into four grades as $\mathrm{V}=$ \{v1 (very good), v2 (good), v3 (average), v4 (bad)\}, score 1 to 10 is assigned, the evaluation rating set can be marked as $V=\left(v_{1}, v_{2}, v_{3}, v_{4}\right)=(10,8,5,3)$.

\subsection{Evaluation Grey Classes.}

The grey number set corresponding to four evaluation grey classes as mentioned earlier is $\otimes=\left(\otimes_{1}, \otimes_{2}, \otimes_{3}, \otimes_{4}\right)$, the whitenization weight function of each grey number is as follows.

$v_{1} \rightarrow \otimes_{1} \in(0,10, \infty)$, whitenization weight function is calculated by formula (5).

$$
f_{1}(x)= \begin{cases}\frac{x}{10} & x \in[0,10] \\ 1 & x \in[10, \infty] \\ 0 & x \in[-\infty, 0]\end{cases}
$$

$v_{2} \rightarrow \otimes_{2} \in(0,8,16)$, whitenization weight function is calculated by formula (6). 


$$
f_{2}(x)= \begin{cases}\frac{x}{8} & x \in[0,8] \\ 2-\frac{x}{8} & x \in[8,16] \\ 0 & x \notin[0,16]\end{cases}
$$

$v_{3} \rightarrow \otimes_{3} \in(0,5,10)$, whitenization weight function is calculated by formula (7).

$$
f_{3}(x)= \begin{cases}\frac{x}{5} & x \in[0,5] \\ 2-\frac{x}{5} & x \in[5,10] \\ 0 & x \notin[0,10]\end{cases}
$$

$v_{4} \rightarrow \otimes_{4} \in(0,3,6)$, whitenization weight function is calculated by formula (8).

$$
f_{4}(x)= \begin{cases}1 & x \in[0,3] \\ 2-\frac{x}{3} & x \in[3,6] \\ 0 & x \notin[0,6]\end{cases}
$$

\subsection{Grey Evaluation Numbers and Fuzzy Matrix.}

It is supposed that the symbol ' $e$ ' represents a certain evaluation grey class, the grey evaluation number for ' $u_{j}$ ' which belongs to ' $e$ ' can be marked as ' $X_{j e}$ ', the formula $X_{j e}=\sum_{l=1}^{p} f_{e}\left(d_{j l}\right)$ is given by formula (5)-(8). All grey evaluation numbers for ' $u_{j}$ ' which belong to all evaluation grey classes is known as $X_{j}=\sum_{e=1}^{g}\left(X_{j e}\right)$.

It is assumed that the grey evaluation weight for ' $u_{j}$ ' which is determined by all experts that belongs to ' $e$ ' is marked as ' $r_{j e}$ ' , and the formula $r_{j e}=\frac{X_{j e}}{X_{j}}$ is known, therefore the grey evaluation weight vector $r_{j}=\left(r_{j 1}, r_{j 2}, \Lambda, r_{j g}\right)$ can be obtained, all grey evaluation weight vectors could form a grey evaluation weight matrix is shown as ' $R$ '.

\subsection{Synthetic Evaluation.}

$$
R=\left[\begin{array}{lll}
r_{11} & \Lambda & r_{1 g} \\
\mathrm{M} & \Lambda & \mathrm{M} \\
r_{j 1} & \Lambda & r_{j g}
\end{array}\right]
$$

The synthetic evaluation result for ' $u_{j}$ ' is marked as ' $B$ ', thus

$$
B=A \circ R=\left(b_{1}, b_{2}, b_{3}, b_{4}\right)
$$

The symbol ' $\mathrm{o}$ ' in the formula (9) is a fuzzy compositional operation symbol which expresses weighted mean.

The synthetic evaluation result ' $B$ ' is a vector which expresses the degree classification description about synthetic condition of evaluation object. Grey class level of evaluation result can be determined with the maximum membership principle. Because of too much information loss, these judgment rules will often fail. Therefore, the vector ' $B$ ' needs to be further processed.

Finally, the evaluation rating vector ' $V$ ' is used to calculate the evaluation value of target layer marked as ' $O$ ' with the formula $O=B \mathrm{oV}^{T}$. The optimal site is selected according to the size of each site evaluation value.

\section{Site Selection Evaluation of Mile General Airport in Yunnan}

\subsection{Alternative Sites Introduction.}

In the initial selection process, alternative sites should avoid the planning scope of central city, the protection area of drinking water source, the reservoir and the surrounding forbidden area, and the local urban and rural overall planning should also be considered. When the key alternative sites are determined, factors such as the distribution of surrounding airport, the traffic planning of local railway, 
highway, national road, provincial road, etc., the key features of topography and geomorphology are also needed to be considered. For Mile airport, preliminary sites should be located in the area within 20 kilometers around the municipal building. Because there are high mountains and reservoir basin on both sides of the area, at the same time, many kinds of important traffic lines, such as GangdongKuming expressway, YunGui high-speed railway, MiMeng railway, etc.are considered, priority selection is given in the central region of the area which is between the mountains on both sides and the flat area in the northwest, nine alternative sites were selected.

First of all, site survey was taken on account of a lot of necessary conditions, such as obstacle free airspace, supporting facilities, compensation for land expropriation and housing demolition, land nature, engineering geology, and environmental protection. Then, six disqualified sites were abandoned after soliciting opinions from the municipal government and relevant departments. The Miyang industrial park site, the Dongfeng farm No. 1 site and the Dongfeng Farm No. 2 site entered the final evaluation stage.

MI yang industrial park site.

The site which is about 4.9 kilometers away from the city center is located on the west side of Miyang industrial park in Miyang town, the nearest road is about 7.3 kilometers from the site. In the future, the datum mark coordinates of the runway are $103^{\circ} 26^{\prime} 2^{\prime \prime} \mathrm{E}$ and $24^{\circ} 21^{\prime} 44^{\prime \prime} \mathrm{N}$, the runway length is 1500 meters, and the aerodrome elevation is 1500 meters. The site is intended to cover an area of $741.61 \mathrm{mu}$, among which the cultivated land (non basic farmland) is $702.05 \mathrm{mu}$, the woodland is $19.87 \mathrm{mu}$, the garden land is $1.39 \mathrm{mu}$ and the construction land is $18.30 \mathrm{mu}$. A total of $723.31 \mathrm{mu}$ of land is not in line with the overall planning of local land use, but the land planning can be adjusted in the next year. There are one county road and two township roads around the site, and the expected cost of the airport connection road is 15 million yuan. About 500 meters of township roads will be occupied by the site, and it will cost 1.2 million yuan to built a new road which is about 1500 meters. The estimated total investment of the airport at this site is 280 million yuan. The terrain within the scope of this site is flat, clearance condition is good in addition to two high-voltage towers near the site. There is no space conflict, the distance between resettlement area and new airport is moderate after house demolition, and the aircraft noise has less influence on surrounding residents.

Dongfeng farm No. 1 site.

The site which is about 15.2 kilometers away from the city center is located on the southwest side of Dongfeng farm and the south side of Sanjiaodi village, the nearest road is about 20.7 kilometers from the site. In the future, the datum mark coordinates of the runway are $103^{\circ} 23^{\prime} 9^{\prime \prime} \mathrm{E}$ and $24^{\circ} 17^{\prime} 28^{\prime \prime} \mathrm{N}$, the length of the runway is 1500 meters, and the aerodrome elevation is 1438 meters. The site is intended to cover an area of $718.89 \mathrm{mu}$, among which the cultivated land is $134.2 \mathrm{mu}$, the woodland is 218.65 $\mathrm{mu}$, the garden land is $366.04 \mathrm{mu}$ and all construction land is in line with the overall planning of local land use. The main road near the site is Hudong road, which is a cement concrete pavement with a width of 14 meters. The expected cost of the airport connection road is 15 million yuan. The terrain within the scope of this site is undulating, the estimated total investment of the airport at this site is 580 million yuan, among which the cost of earth and stone project is about 280 million. A large number of unmoved residents will be closer to the new airport and noise pollution could be serious. At the same time, the environment on surrounding farm will be polluted after the airport completion. There is no space conflict. Because of the good ecological environment around this site, the activities of birds are frequent.

Dongfeng farm No. 2 site.

The site which is about 14.7 kilometers away from the city center is located on the south side of Dongfeng farm and the east side of Daxindi village, the nearest road is about 16.7 kilometers from the site. In the future, the datum mark coordinates of the runway are $103^{\circ} 24^{\prime} 31^{\prime \prime} \mathrm{E}$ and $24^{\circ} 17^{\prime} 29^{\prime \prime} \mathrm{N}$, the length of the runway is 1500 meters, and the aerodrome elevation is 1426 meters. The site is intended to cover an area of $778.4 \mathrm{mu}$, among which the cultivated land is $209.7 \mathrm{mu}$, the woodland is 287.05 $\mathrm{mu}$, the garden land is $281.65 \mathrm{mu}$ and all construction land is in line with the overall planning of local land use. The main road near the site is Guangdong-Kunming expressway with four traffic lanes, which is a asphalt concrete pavement with a width of 26 meters. After the airport road is connected 
to Minan connecting line, vehicles can reach the surrounding area quickly, and the cost of the connecting road construction could be about 27 million yuan. The terrain within the scope of this site is flat, the geographical conditions are superior, and the estimated total investment of the airport at this site is 290 million yuan. Due to integral removal of the Daxindi village, the airport is far from the surrounding residents after its completion, and there is no aircraft noise pollution. The environment on surrounding farm will be polluted. Because of the good ecological environment around this site, the activities of birds are frequent. There is no space conflict.

\subsection{Site Evaluation.}

1) Calculation of index weight

Two professors from Guangzhou Civil Aviation College and Civil Aviation University of China, and two senior engineers who participated in the airport site selection graded three alternative sites according to the actual situation, the evaluation sample matrices ' $D_{1}$ ', ' $D_{2}$ ' and ' $D_{3}$ ' (The data is omitted) are obtained. The average value of the scores given by the above four experts is calculated for each site, the evaluation matrix ' $D$ ' ' is also obtained as shown below.

$$
D^{\prime}=\left[\begin{array}{llllllllllllllllllll}
2 & 8 & 7 & 9 & 7 & 6 & 8 & 7 & 8 & 8 & 9 & 7 & 6 & 8 & 6 & 6 & 7 & 6 & 9 & 8 \\
8 & 8 & 6 & 4 & 8 & 4 & 7 & 4 & 6 & 8 & 9 & 8 & 7 & 8 & 6 & 7 & 7 & 8 & 9 & 6 \\
7 & 8 & 8 & 7 & 6 & 9 & 7 & 4 & 8 & 8 & 9 & 8 & 7 & 7 & 5 & 6 & 9 & 8 & 9 & 6
\end{array}\right]
$$

The index weight with the entropy method can be obtained by replacing the data in the matrix $D^{\prime}$ into the formula (1), (2) and (3), as shown in Table2.

Table 1. Evaluation index system of general airport site

\begin{tabular}{|c|c|c|}
\hline Target layer & First layer & Second layer \\
\hline \multirow{20}{*}{$\begin{array}{l}\text { general airport site } \\
\text { evaluation } \\
(U)\end{array}$} & \multirow{3}{*}{ planning requirements } & coordination with local town and country planning $\left(u_{1}\right)$ \\
\hline & & coordination with adjacent Airports $\left(u_{2}\right)$ \\
\hline & & coordination with other modes of transportation $\left(u_{3}\right)$ \\
\hline & \multirow{5}{*}{$\begin{array}{l}\text { economy and } \\
\text { environment }\end{array}$} & construction cost of project $\left(u_{4}\right)$ \\
\hline & & $\begin{array}{c}\text { compensation for housing demolition and land } \\
\text { requisition }\left(u_{5}\right)\end{array}$ \\
\hline & & noise pollution $\left(u_{6}\right)$ \\
\hline & & air and water pollution $\left(u_{7}\right)$ \\
\hline & & ecological and environmental impact $\left(u_{8}\right)$ \\
\hline & \multirow{7}{*}{$\begin{array}{l}\text { technical conditions of } \\
\text { project }\end{array}$} & topographical conditions $\left(u_{9}\right)$ \\
\hline & & $\begin{array}{l}\text { conditions of engineering geology and hydrogeology } \\
\qquad\left(u_{10}\right)\end{array}$ \\
\hline & & underground mineral deposits and cultural relics $\left(u_{11}\right)$ \\
\hline & & $\begin{array}{l}\text { site conditions of construction, reconstruction and } \\
\text { extension }\left(u_{12}\right)\end{array}$ \\
\hline & & surrounding public facilities $\left(u_{13}\right)$ \\
\hline & & drainage and flood control conditions $\left(u_{14}\right)$ \\
\hline & & aviation fuel supply conditions $\left(u_{15}\right)$ \\
\hline & \multirow{5}{*}{ operation safety } & weather conditions $\left(u_{16}\right)$ \\
\hline & & clearance conditions $\left(u_{17}\right)$ \\
\hline & & electromagnetic environment $\left(u_{18}\right)$ \\
\hline & & airspace conditions $\left(u_{19}\right)$ \\
\hline & & bird strike hazard $\left(u_{20}\right)$ \\
\hline
\end{tabular}

Table 2. Index weight with the entropy method and the AHP

\begin{tabular}{|c|c|c|c|c|c|c|c|c|c|c|}
\hline Index & $u_{1}$ & $u_{2}$ & $u_{3}$ & $u_{4}$ & $u_{5}$ & $u_{6}$ & $u_{7}$ & $u_{8}$ & $u_{9}$ & $u_{10}$ \\
\hline $\boldsymbol{w}_{\boldsymbol{j}}^{\prime}$ & 0.3845 & 0.0003 & 0.0206 & 0.1515 & 0.0206 & 0.1598 & 0.0057 & 0.1155 & 0.0253 & 0.0003 \\
\hline $\boldsymbol{w}_{\boldsymbol{j}}^{\prime \prime}$ & 0.0333 & 0.0522 & 0.0111 & 0.0159 & 0.0159 & 0.0333 & 0.0522 & 0.0522 & 0.0111 & 0.0535 \\
\hline Index & $u_{11}$ & $u_{12}$ & $u_{13}$ & $u_{14}$ & $u_{15}$ & $u_{16}$ & $u_{17}$ & $u_{18}$ & $u_{19}$ & $u_{20}$ \\
\hline $\boldsymbol{w}_{\boldsymbol{j}}^{\prime}$ & 0.0003 & 0.0057 & 0.0081 & 0.0057 & 0.0103 & 0.0083 & 0.0226 & 0.0253 & 0.0003 & 0.0293 \\
\hline $\boldsymbol{w}_{\boldsymbol{j}}^{\prime \prime}$ & 0.0330 & 0.0522 & 0.0149 & 0.0854 & 0.0110 & 0.0854 & 0.0854 & 0.0854 & 0.1312 & 0.0854 \\
\hline
\end{tabular}


For all Second layer indexes, the judgment matrix is constructed with the AHP, then the index weight is obtained after the maximum eigenvalue is calculated and normalized, as shown in Table2. It is calculated that the consistency ratio meets the requirement.

The data in Table 1 and Table 2 are replaced into the formula (4), the synthetic weight of index is obtained, as shown in Table3.

Table 3. Index synthetic weight

\begin{tabular}{|c|c|c|c|c|c|c|c|c|c|c|}
\hline Index & $u_{1}$ & $u_{2}$ & $u_{3}$ & $u_{4}$ & $u_{5}$ & $u_{6}$ & $u_{7}$ & $u_{8}$ & $u_{9}$ & $u_{10}$ \\
\hline$w_{j}$ & 0.3547 & 0.0005 & 0.0063 & 0.0667 & 0.0091 & 0.1474 & 0.0082 & 0.1670 & 0.0078 & 0.0004 \\
\hline Index & $u_{11}$ & $u_{12}$ & $u_{13}$ & $u_{14}$ & $u_{15}$ & $u_{16}$ & $u_{17}$ & $u_{18}$ & $u_{19}$ & $u_{20}$ \\
\hline$w_{j}$ & 0.0004 & 0.0082 & 0.0033 & 0.0135 & 0.0031 & 0.0196 & 0.0535 & 0.0599 & 0.0011 & 0.0693 \\
\hline
\end{tabular}

Calculation of grey evaluation weight matrix

The the grey evaluation number for the index ' $u_{1}$ ' in the matrix ' $D_{1}$ ' which belongs to the first grey class can be calculated by formula (5), (6), (7), and (8). In the same way, the grey evaluation number which belongs to the second, the third and the fourth grey class is known.

$$
X_{11}=f_{1}(3)+f_{1}(2)+f_{1}(2)+f_{1}(1)=0.8, X_{12}=1, X_{13}=1.6, X_{14}=4
$$

The total grey evaluation number for ' $u_{1}$ ' which belongs to each grey class can be calculated as $X_{1}=\sum_{e=1}^{4} X_{1 e}=7.4$, and the weight vector of grey evaluation for ' $u_{1}$ ' is obtained as follows.

$$
\begin{gathered}
r_{1}=\left(r_{11}, r_{12}, r_{13}, r_{14}\right)=\left(\frac{0.8}{7.4}, \frac{1}{7.4}, \frac{1.6}{7.4}, \frac{4}{7.4}\right) \\
=(0.1082,0.1351,0.2162,0.5405)
\end{gathered}
$$

The above steps are repeated, grey evaluation weight vectors for the other nineteen indexes in the matrix ' $D_{1}$ ' are calculated. Then, the grey evaluation weight matrix ' $R_{1}$ ' is obtained. In the same way, the grey evaluation weight matrices ' $R_{2}$ ' and ' $R_{3}$ ' of the matrices ' $D_{2}$ ' and ' $D_{3}$ ' can also be calculated.

Calculation of evaluation result

The synthetic evaluation for the target layer of three alternative sites is made respectively, three evaluation result vectors will be obtained by formula (9) as follows.

$$
\begin{aligned}
& B_{1}=A \circ R_{1}=(0.2525,0.3045,0.2407,0.2023) \\
& B_{2}=A \circ R_{2}=(0.2828,0.3405,0.2658,0.1109) \\
& B_{3}=A \circ R_{3}=(0.3245,0.3850,0.2399,0.0506)
\end{aligned}
$$

Finally, evaluation values of three alternative sites for Maitreya general airport are calculated by the evaluation rating vector $V=(10,8,5,3)$ and the formula $O=B \mathrm{o} V^{T}$, as shown follows.

$$
O_{1}=6,7714, O_{2}=7.2137, O_{3}=7.6763
$$

According to the evaluation value, Dongfeng farm No. 2 site is the best, which should be reported to the relevant department for the final site.

\section{Conclusion}

Index weights are measured by the synthetic weighting method which is combined the AHP with the entropy method to realize the organic combination of objective and subjective weight. Various kinds of grey information are fully utilized in the process of grey fuzzy evaluation to prevent lack fidelity of the evaluation results. In summary, the useful information contained in the evaluation value is maximized by the grey fuzzy evaluation model based on synthetic weighting method, it can improve the scientificity of evaluation results and reduce the influence of individual subjective factors. It is found that the evaluation results are consistent with the actual results after the application of the model, and it shows that the method has strong operability and applicability, it also provides a reference for general airport site selection. 


\section{References}

[1]. Civil Aviation Issued[2017]No.46. General Airport Sort Management Regulations[S]. Beijing: Civil Aviation Administration of China, 2017.

[2]. Liaoyong,XinpingZhu.The optimization of airport site selection based on stochastic programmi ng[J]. Science Technology and Engineering, 2016, 16(18): 294-298.

[3]. Yongqiang Guo, Shaobin, Guanhu Wang, et al. Application of the multiple echelons gray comprehensive evaluation method on the selection of heliport[J]. Environmental Engineering, 2015(33): 692-694.

[4]. Jiaoe Wang, Huihui Mo. Discussion on the layout method of civil aviation airport[J]. Journal of Civil Aviation Flight University of China, 2009, 20(06): 7-10.

[5]. Mingjie Li, Shirong. Site selection assessment model for civil aerodrome based on catastrophe assessment method[J]. Journal of Civil Aviation University of China, 2011, 29(06): 35-37+54.

[6]. Ding D L, Cai L C, Wang X L, et al. Application of comprehensive evaluation of the airport site selection[J]. Applied Mechanics and Materials, 2011: 97-98+311-315.

[7]. Chen X M,Liu Q X,Du G. Estimation of travel time values for Urban public transport Passengers Based on SP Survey[J]. Journal of Transportation Systems Engineering and Information Technology,2011,11(4) :77-84.

[8]. MH/T 5026-2012. General Airport Construction Code[S]. Beijing: Civil Aviation Administration of China, 2012. 